\title{
SOBREPOSIÇÃO \\ DE LÍNGUAS: \\ DESCRIÇÕES \\ LINGUÍSTICAS
}

\section{SUPERPOSICIÓN DE LENGUAS: DESCRIPCIONES LINGÜÍSTICAS}

\author{
BLENDING LANGUAGES: LINGUISTIC DESCRIPTIONS
}

Ronice Müller de Quadros*

Universidade Federal de Santa Catarina

Diane Lillo-Martin **

University of Connecticut

Marilyn Mafra Klamt***

Universidade Federal de Santa Catarina

\begin{abstract}
RESUMO: Este artigo apresenta o fenômeno da sobreposição de línguas em bilíngues bimodais, que apresentam um bilinguismo simultâneo peculiar, pois as línguas que adquirem ao longo do desenvolvimento linguístico envolvem diferentes modalidades: língua de sinais e língua falada. A investigação que dá origem a esse estudo trabalha com dois pares de línguas: língua brasileira de sinais (Libras) e língua portuguesa brasileira (PB) e língua de sinais americana (ASL) e língua inglesa americana (EA). Na análise da produção simultânea, é possível verificar a combinação das línguas na sobreposição e os possíveis impactos disso na constituição de bilíngues bimodais, bem como compreender o fenômeno linguístico do bilinguismo. Os resultados apresentados focam no par Libras e PB, embora haja um paralelo próximo encontrado no par ASL e EA. Os aspectos gramaticais abordados envolvem dois tipos de construções na produção sobreposta: passivas e causativas, em que ocorre uma convergência consistente evidenciando a síntese das línguas.
\end{abstract}

PALAVRAS CHAVE: Bilinguismo bimodal. Desenvolvimento bilíngue. Sobreposição de línguas.

RESUMEN: Este artículo presenta el fenómeno de la superposición de lenguas en bilingües bimodales, que presentan un peculiar bilingüismo simultáneo, ya que las lenguas adquiridas durante el desarrollo lingüístico involucran diferentes modalidades: lengua de señas y lengua hablada. La investigación que dio lugar a este estudio trabaja con dos pares de lenguas: lengua de señas brasileña (Libras) y lengua portuguesa de Brasil (PB) y lengua de señas estadounidense (ASL) e inglés americano (EA). En el análisis de la

\footnotetext{
* Ronice Müller de Quadros é professora e pesquisadora da Universidade Federal de Santa Catarina, no Departamento de Librase pesquisadoradoCNPQ.E-mail: ronice.quadros@ufsc.br.

** Diane Lillo-Martiné professora e pesquisadorada University of Connecticut. E-mail:diane.lillo-martin@uconn.edu. 
producción simultánea, es posible verificar la combinación de lenguas en el solapamiento y los posibles impactos de esta en la constitución de bilingües bimodales, así como comprender el fenómeno lingüístico del bilingüismo. Los resultados presentados se centran en el par Libras y PB, aunque existe un estrecho paralelo en el par ASL y EA. Los aspectos gramaticales cubiertos involucran dos tipos de construcciones en la producción superpuesta: pasiva y causativa, en las que hay una convergencia consistente que muestra la síntesis de lenguajes.

PALABRAS CLAVE: Bilingüismo bimodal. Desarrollo bilingüe. Superposición de lenguas.

ABSTRACT: This article presents the phenomenon of blending of languages in bimodal bilinguals. For bimodal bilinguals, the languages acquired during linguistic development involve different modalities: a sign language and a spoken language. Because the languages are expressed in different modalities, it is possible to produce structures using both languages simultaneously. We use such productions to better understand the architecture of bilingual linguistic systems both in general and for bimodal bilinguals in particular. The investigation that gave rise to this study works with two pairs of languages: Brazilian sign language (Libras) with Brazilian Portuguese (PB), and American Sign Language (ASL) with American English (EA). The results presented here focus on the pair Libras and PB, although there is a close parallel found in the pair ASL and EA. The grammatical aspects covered involve two types of constructions in blending production: passives and causatives. The bimodal productions show a consistent convergence as provided by our view of the synthesis of languages.

KEYWORDS: Bimodal bilingualism. Linguistic development. Code-blending.

\section{INTRODUÇÃO}

Os bilíngues bimodais são aqueles que possuem duas línguas em modalidades diferentes: uma visual-espacial (língua de sinais) e uma oral-auditiva (língua falada). Esses bilíngues apresentam características já identificadas em outros bilíngues que são decorrentes do contato íntimo entre as duas línguas pela mesma pessoa, gerando possibilidades desdobradas do fenômeno de transferência entre línguas. Um exemplo comum é a alternância de línguas (code-switching) como um subconjunto da mistura de línguas (code-mixing). No entanto, no caso específico dos bilíngues bimodais, encontramos ainda uma forma de misturar as línguas bastante peculiar que é a sobreposição de línguas (code-blending). Esse último fenômeno é possível somente com bilíngues bimodais, por causa das línguas que utilizam diferentes canais de articulação, ou seja, as línguas de sinais utilizam (mãos, face, tronco) e as línguas faladas utilizam a boca e os ouvidos. Assim, essas línguas podem ser combinadas simultaneamente, o que não é possível de ser observado em outros bilíngues unimodais (línguas na mesma modalidade).

Os bilíngues bimodais, que foram estudados na pesquisa apresentada neste artigo, são filhos ouvintes de pais surdos, embora possam ser quaisquer pessoas que produzam as línguas em diferentes modalidades. Os filhos ouvintes de pais surdos são chamados de Codas (children of deaf adults) de forma genérica e Kodas de forma específica para as crianças pequenas (kids of deaf adults). Nós utilizamos o termo Codas para os participantes da nossa pesquisa, mas podemos eventualmente utilizar o termo Kodas seguindo a forma usada pelos artigos que serão mencionados ou por especificar que estamos nos referindo às crianças ouvintes pequenas. No entanto, nosso estudo apresentado aqui envolve apenas aos adultos ouvintes, filhos de pais surdos.

Quadros (2017) explica que os Codas podem ser considerados falantes/sinalizantes de língua de herança, ou seja, aqueles que crescem em uma família que usa uma língua diferente da língua usada no entorno social maior. No caso brasileiro, os Codas nascem nas famílias que usam a Libras em casa com seus pais e a Língua Portuguesa na maior parte dos espaços sociais em que interagem com outras pessoas da comunidade (escolas, igrejas, clubes, etc.).

Quadros (2017) observou que a L1 e a L2 podem ser língua primária ou secundária para os bilíngues bimodais balanceados a depender do contexto sociolinguístico, já que eles podem alternar as línguas dependendo de seu interlocutor. Na sobreposição especificamente, em que são usados diferentes canais de articulação para sobrepor a língua oral e a língua sinalizada, podem alternar entre uma e outra língua a condição de língua primária, ou seja, escolhem a língua que irá dirigir a derivação sintática em uma proposição. Outros autores definem essa língua que dirige a derivação como língua matriz (EMMOREY et al., 2008). Já os bilíngues bimodais desbalanceados têm a sua L1, a Libras, como língua secundária e a L2, o Português, assume a condição de língua primária. 
Neste caso, eles não apresentam alternância entre língua primária e língua secundária e a derivação sintática se origina do Português, utilizando elementos da língua secundária. O modelo de síntese explica estas possibilidades.

O modelo de síntese aplicado aos bilíngues bimodais foi apresentado pela primeira vez por Lillo-Martin et al. (2010) e, posteriormente por Lillo-Martin et al. (2016). Este modelo teórico apresenta um sistema computacional no qual diferentes línguas podem ser sintetizadas durante o processo de derivação da sentença. Esta proposta segue modelos já elaborados para a alternância de línguas em bilíngues (MACSWAN, 2000, 2005). O modelo não é de produção on-line, mas de derivação incorporando pressupostos da sintaxe gerativa minimalista (CHOMSKY, 1995). Nós adotamos também a Morfologia Distribuída (HALLE; MARANTZ, 1993) associada a este modelo, seguindo propostas de outros pesquisadores, tais como Pierantozzi (2012). No entanto, o modelo de síntese também considera a possibilidade de duas interfaces articulatórias: uma para as línguas faladas e outra para as línguas de sinais. Assim, damos conta da sobreposição das duas línguas de forma simultânea. O modelo de síntese está apresentado na figura 1.

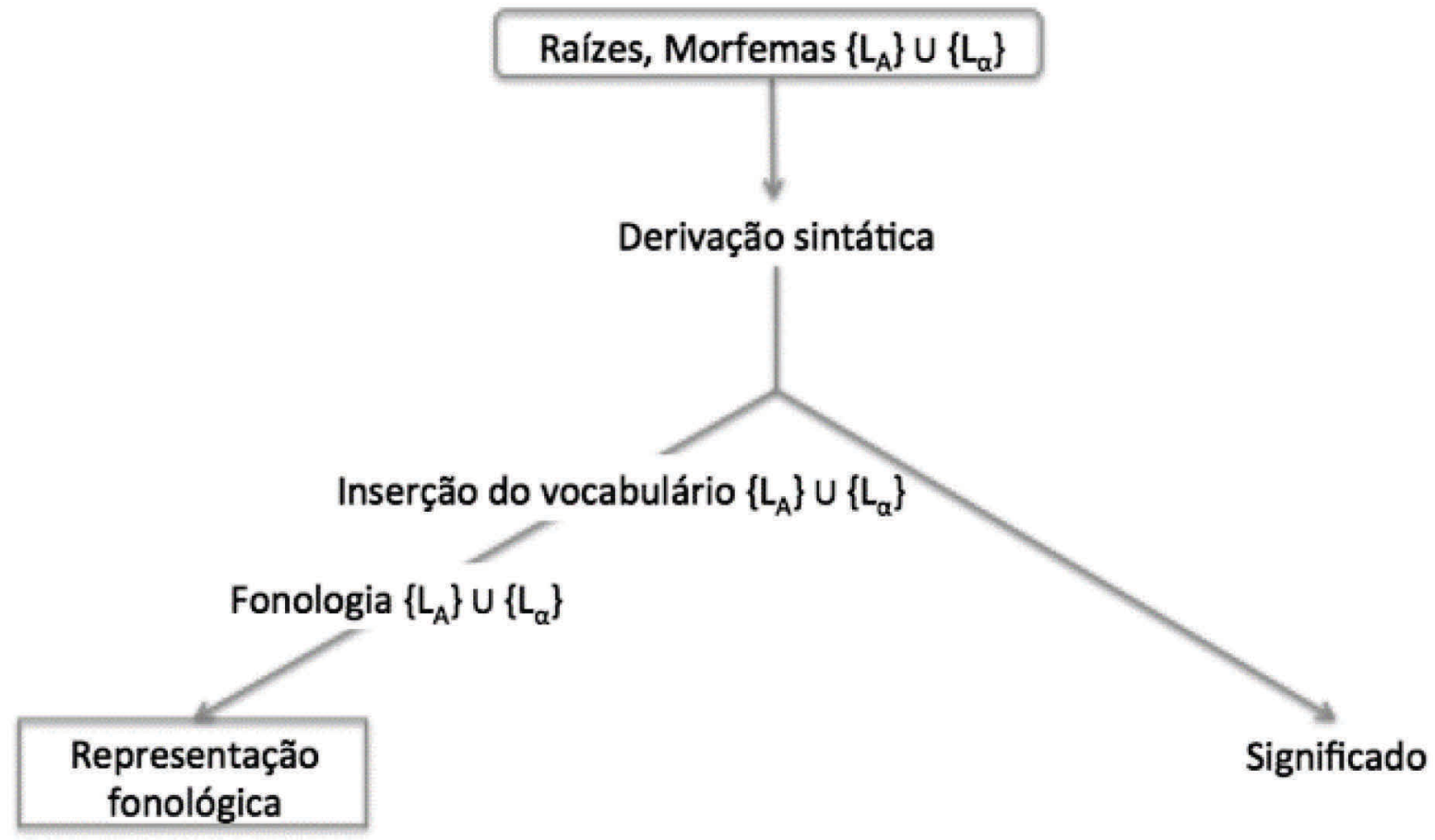

Figura 1: Modelo de Síntese de Línguas

Fonte: Lillo Martin et al. (2016)

Os casos mais simples de sobreposição de línguas envolvem duas palavras que são equivalentes de tradução inseridos na derivação: uma no sinal e outra na fala. Estes casos de co-inserção ocorrem frequentemente na sobreposição de línguas. É um fenômeno linguístico que traz questionamentos importantes do ponto de vista teórico. É importante especificar que embora haja várias instâncias de co-inserção em uma única sentença, não é o caso de que o mapeamento entre os sinais e a fala seja um a um. A sobreposição não é um Português Sinalizado (comunicação simultânea artificial) que submete a Libras ao Português incluindo gestos para completar os elementos da fala com o intuito de ensinar a estrutura dessa língua em detrimento da Libras. Em contraste, a sobreposição é uma produção natural em contextos bimodais (dois modos, sinais e fala) que reflete tanto a gramática da língua de sinais, quanto da língua falada, com nuances prosódicas das duas línguas (VAN DEN BOGAERDE; BAKER, 2002).

Neste artigo, estamos apresentando alguns resultados do estudo com Codas adultos, considerando especificamente as estruturas causativas e passivas, no sentido de verificar se o modelo de síntese se aplica ou não. Essas estruturas são interessantes, exatamente por apresentarem uma forma de estruturação gramatical diferente nas línguas de sinais e nas línguas faladas (estruturas 
incongruentes, não convergentes do ponto de vista sintático). Vamos analisar em mais detalhes a sobreposição das línguas na derivação destas estruturas, especialmente, no par de línguas Libras e PB.

\section{ESTUDOS ANTERIORES SOBRE O BILINGUISMO BIMODAL E O MODELO DE SÍNTESE}

Os estudos com bilíngues bimodais iniciaram com a aquisição da linguagem (VAN DEN BOGAERDE; BAKER, 2002). Chen Pichler et al. (2016), Lillo-Martin et al. (2010,2014, 2016) e Quadros et al. (2012, 2014) realizaram um estudo com crianças bilíngues bimodais nos Estados Unidos e no Brasil entre 18 meses e seis anos de idade (estudo longitudinal e experimental). Os estudos experimentais com crianças entre quatro e oito anos de idade incluíram diferentes aspectos gramaticais: fonológicos, morfológicos, lexicais, sintáticos e discursivos (QUADROS et al., 2015). O foco destes estudos foi a análise do desenvolvimento bilíngue bimodal, observando-se como as crianças misturavam as línguas. As autoras constataram que as crianças usam as estruturas gramaticais de forma apropriada em uma língua com palavras da outra língua simultaneamente. Isso não caracteriza a alternância de línguas, pois as crianças combinavam as duas línguas simultaneamente, o que passamos a chamar de sobreposição de línguas, seguindo a proposta de Emmorey et al. (2008). As autoras também observaram que as crianças procuram usar as duas línguas de forma congruente, ou seja, produzindo estruturas comuns entre as duas línguas, privilegiando as estruturas que sejam gramaticais em ambas as línguas.

Um dos estudos destas autoras (LILLO-MARTIN et al., 2014) focou na produção de quatro crianças bilíngues bimodais (duas americanas e duas brasileiras), observando, que por volta dos dois anos, elas já mostram sensibilidade ao interlocutor e modulam sua escolha linguística a depender de com quem estão interagindo, mas também são influenciadas por outros fatores, como o estilo de comunicação usado em casa ou a percepção da língua falada ser predominante na comunidade. Os dados refletem a produção de mais sentenças sinalizadas com interlocutores surdos e mais fala com interlocutores ouvintes e três das quatro crianças foram também fortemente afetadas pela dominância da língua falada no contexto sociolinguístico da comunidade porque distinguiram entre os contextos de fala e sinais, mostrando preferência pelo uso da fala em ambos os contextos. A outra criança mostrou um padrão de separação dos discursos e preferência por usar mais a produção bimodal do que apenas sinais na seção sinalizada, sendo que sua mãe usa uma estratégia monolíngue mais estrita ao interagir com ela. A pesquisa confirmou que uma maior separação do discurso está relacionada à estratégia monolíngue no recebimento do input caseiro. Lillo-Martin et. al. (2014) observam então que, diferentemente dos bilíngues unimodais que necessariamente precisam inibir uma língua para produzir a outra, os bilíngues bimodais têm a tendência de mesmo em sessões sinalizadas usarem ambas as línguas ou usarem sinais não manuais próprios da língua de sinais enquanto estão produzindo a língua falada. Isto ocorreu com os quatro participantes, mas em um deles a taxa de uso da sobreposição foi maior do que os outros. Inibir completamente uma das línguas implicaria um alto processamento linguístico para os bilíngues bimodais.

Lillo-Martin et al. (2010) e Quadros, Lillo-Martin e Chen-Pichler (2016a) comparam a produção da criança e do adulto bilíngue bimodal e concluem que eles diferem com relação ao desenvolvimento da coordenação da produção bimodal, mas por outro lado ambos fazem uso completo das possibilidades disponíveis no bilinguismo bimodal, combinando aspectos das duas línguas - falada e sinalizada. As crianças surdas com implante coclear desenvolvem o bilinguismo bimodal de forma similar às crianças ouvintes bilíngues bimodais quando expostas desde cedo à língua de sinais. As autoras discutiram o grau de coordenação e congruência das sentenças code-blended e a localização dos elementos-QU nas questões-QU. Com relação à coordenação e congruência, tanto os adultos quanto as crianças produzem estruturas blended e as duas línguas contribuem para uma única proposição. As sentenças em sua maioria são redundantes entre sinais e fala e há uma forte coordenação temporal entre fala e sinais, embora esta coordenação esteja sendo desenvolvida pelas crianças. Com relação à coordenação estrutural em wh question testadas em crianças de 4 a 8 anos, as que estão em estágios mais iniciais de aquisição, em geral usam a estrutura apropriada na língua cujas palavras foram elaboradas, mas existem algumas exceções especiais em que a criança usa estruturas na língua falada que são apenas permitidas para a língua de sinais, como o QU in situ e o QU duplicado. O QU em posição final e in situ são estruturas permitidas em contextos bastante específicos no inglês e no português, mas as crianças bilíngues adquirem estas estruturas mais cedo do que as crianças monolíngues e isto é analisado como um efeito da língua de sinais sobre a língua falada. No caso das crianças mais velhas, foi observado o oposto, ou seja, um maior efeito da língua falada na língua de sinais, pois apesar de elas produzirem uma variedade de tipos estruturais nas 
questões QU, elas seguem na maioria das vezes a ordem de palavras da língua falada, com o QU em posição inicial. A conclusão é de que a síntese de línguas atua em diferentes estágios e em variadas direções (sinais para fala e fala para sinais) e a mudança na língua dominante para as crianças ouvintes bilíngues bimodais, que passa dos sinais para a fala, se dá, principalmente, pela entrada da criança na escola e pela pouca interação com sinalizantes surdos.

O mesmo estudo também trouxe à tona a questão do bilinguismo bimodal das crianças surdas, filhas de pais surdos, com implante coclear que são expostas desde o nascimento à língua de sinais, o que irá influenciar positivamente o aprendizado posterior da língua falada. Elas têm desenvolvimento semelhante às Kodas e isto pode diminuir os efeitos do atraso na aquisição da outra língua. As autoras afirmam que apesar de haver um crescente aumento de estudos com relação à interação entre sinais e fala nas crianças surdas com implante, esta é altamente complexa e depende de uma série de fatores e os resultados desses estudos são por vezes contraditórios. No entanto, quando a criança recebe um acesso irrestrito à língua de sinais natural desde seu nascimento esta exposição não acarreta prejuízo à língua falada. Outro grupo descrito é o de intérpretes de língua de sinais, Codas ou não, que também são bilíngues bimodais, com a diferença de que por seu treinamento e habilidades profissionais lidam com padrões específicos na interação entre as línguas, como por exemplo: adicionar vocabulário de uma língua em outra, movimentação da boca durante a sinalização com configurações de boca da língua de sinais e uso simultâneo das duas línguas (code-blending). Além disso, eles podem aumentar a inibição da outra língua se comparada à produção dos bilíngues bimodais não intérpretes. Tanto as crianças e os adultos bilíngues bimodais como as crianças bilíngues bimodais com implante coclear usam a síntese de línguas, mas as crianças ainda estão em desenvolvimento com relação aos contextos code-blending. O modelo de síntese dá conta de todas as misturas de línguas ativadas pelos bilíngues bimodais, como o code switching, o code blending, o blending parcial e as sentenças produzidas com características da outra língua. O resultado é uma única derivação no nível fonológico, sendo os materiais inseridos de ambas as línguas congruentes no nível sintático.

Com adultos Codas, Quadros et al. (2016a, 2016b) estudaram a produção simultânea de língua oral e língua de sinais dos Codas, procurando entender como a língua de sinais e a língua oral, que são de diferentes modalidades, interagem e quais os efeitos linguísticos dessas interações. A sobreposição sempre envolve uma proposição e uma derivação sintática e, de acordo com o modelo de síntese, as línguas seguem uma computação sintática e inserem elementos morfológicos das duas línguas. As autoras observaram que quando a língua de sinais rege a derivação sintática, ou seja, quando é língua primária, há efeitos na prosódia da fala, como ajustes na fala para acomodar os sinais, preenchedores sonoros durante a sinalização, omissões na língua falada. Além disso, também foram observadas intrusões da língua falada, como o uso de soletração e palavras funcionais, como preposições, artigos, conjunções, pronomes e verbos auxiliares. Além disso, pode haver transferências semânticas na sobreposição, ou seja, termos de uma língua podem fazer parte de termos mais abrangentes na outra língua, como nos exemplos BIRD em ASL e Tweety em inglês; SINAIS em Libras e fala em Português; SOLETRAR em Libras e escrever em português. Quando ocorreram incongruências entre fala e sinais (no par Libras/Português), isto poderia indicar duas derivações sendo processadas simultaneamente, no entanto estas ocorrências ocorrem na mesma fase de derivação e, portanto, são permitidas pelo modelo de síntese. A conclusão das autoras é de que na sobreposição são feitos ajustes de uma língua para outra ou das duas línguas permitindo preservar a derivação sintática em uma computação única em cada proposição.

A proposta de Quadros (2019) é a de descrever fenômenos linguísticos nas produções de sinalizantes bilíngues bimodais com diferentes fluências na Libras, aliando os modelos de Emmorey et al. (2008) e Lillo-Martin et. al. (2010, 2014, 2016). No primeiro modelo, as produções sincronizadas na sobreposição alternam as duas línguas (ASL e inglês) como língua matriz, sendo esta que dirige a derivação e a outra língua acomoda-se a sua estrutura. No entanto, nem sempre é possível identificar qual a língua matriz, já que algumas produções sobrepostas são gramaticais em ambas as línguas. No modelo de síntese, há uma única derivação na qual são inseridos elementos das duas línguas, que estão ativas. As estruturas sintáticas e semânticas das duas línguas são congruentes e sincronizadas do ponto de vista do modelo de síntese. Isto ocorre por haver um esforço dos bilíngues bimodais de disponibilizar sentenças que sejam compatíveis nas duas línguas e, quando isso não é possível, uma das duas línguas dirige a derivação e a outra se acomoda à sua estrutura. Considerando estes dois modelos, portanto, a autora analisou dados de bilíngues bimodais com diferentes níveis de fluência, observando a eleição de uma língua primária (matriz) para as produções. A alternância na escolha da língua primária ocorre especialmente entre os bilíngues bimodais balanceados. No caso dos desbalanceados, houve preferência pela língua mais forte, ou quando o contexto favoreceu a outra língua como primária, a estrutura da língua mais forte se acomodou à língua 
primária. Portanto, ainda que uma das línguas esteja adormecida, ambas encontram-se ativadas, de acordo com o modelo de síntese. Alguns fenômenos observados pela autora foram: efeitos morfológicos da língua primária na língua secundária como a não marcação de gênero e número; flexão verbal que não ocorre na língua secundária ou a repetição do verbo no português considerando o movimento reiterativo realizado na Libras como marca aspectual; omissão de verbos auxiliares ou outras palavras funcionais no português; omissão de palavras no português quando há itens complexos na Libras e não há uma tradução equivalente, como no caso dos descritivos visuais (DV). Apesar de haver diferentes níveis de fluência e os bilíngues bimodais balanceados conseguirem produzir mais sentenças gramaticais nas duas línguas simultaneamente, observou que houve um padrão de regularidade nas estruturas sobrepostas - a sintaxe geralmente é congruente pois os bilíngues bimodais evitam uma ordem conflitante entre a sintaxe das línguas ou então é feita uma acomodação sintática, ou seja, a síntese de línguas acontece por meio de uma única derivação.

O estudo apresentado aqui vai continuar estas análises considerando estruturas que apresentam uma estrutura gramatical diferente nas línguas de sinais e nas línguas faladas, mais especificamente, na Libras e no PB. O fato destas línguas apresentarem nestes tipos de construção formas sintáticas diferentes torna o estudo mais interessante no sentido de verificar se realmente a síntese das línguas é privilegiada ou não. A congruência das duas línguas observada até então se aplica a estruturas que apresentam uma forma similar nas duas línguas. Assim, se a síntese de línguas realmente acontece, os bilíngues bimodais precisarão evitar a sobreposição de estruturas que não sejam as mesmas nas diferentes línguas ou submeter uma língua a outra, no caso, a língua secundária à língua primária no processo de derivação para garantir a congruência sintática por meio da síntese. Alternativamente, os bilíngues bimodais devem buscar outras estratégias para manter a síntese das línguas buscando a convergência e mantendo condições felizes na interação comunicativa.

\section{A SOBREPOSIÇÃO NOS CODAS ADULTOS BILÍNGUES BIMODAIS}

A presente pesquisa investiga a faculdade da linguagem da perspectiva de bilíngues bimodais, ou seja, bilíngues em uma língua de sinais e uma língua falada. Os participantes envolvem adultos ouvintes, filhos de pais surdos, que adquiriram a língua de sinais em casa com seus pais e a língua falada na sociedade em geral (PRESTON, 1995; BISHOP; HICKS, 2005; QUADROS, 2017), ou seja, os Codas. Como mencionado na introdução, o bilinguismo dos Codas é conhecido como bilinguismo bimodal, um tipo de bilinguismo que tem recebido atenção, pois apesar de apresentarem várias características identificadas em bilíngues unimodais, eles apresentam especificidades muito interessantes. Nosso foco principal envolve exatamente tais especificidades, ou seja, investigar a sobreposição de línguas, que envolve a produção simultânea das línguas faladas e sinalizadas, com o objetivo de refinar a proposta teórica de síntese de línguas (LILLO-MARTIN et al., 2010, 2016).

Os dados foram coletados usando experimentos que incluíram entrevistas, produções de narrativas, elicitação de dados e julgamento de gramaticalidade. Nossa pesquisa focou nas características linguísticas dos participantes analisando suas produções em três diferentes modos: fala, sinais e a combinação de sinais e fala sobreposta (produção bimodal simultânea). O presente artigo analisa os dados coletados na tarefa de elicitação de sobreposição das línguas. Enquanto bilíngues, Codas apresentam alternância de línguas, além da sobreposição, produzindo uma mistura criativa regrada. Os estudos já verificaram que a alternância de línguas é uma manifestação linguística de bilíngues bastante regrada tanto no nível lexical, como no estrutural (por exemplo, POPLACK, 1980). Ao estudar de forma mais detalhada a sobreposição de línguas, será possível identificar se as restrições identificadas na alternância de línguas que são impostas pela linearidade estão relacionadas com aspectos da produção, ou se são restrições que estão entranhadas no sistema linguístico, no sentido que, mesmo quando questões impostas pelo sistema articulatório não se apliquem (caso da sobreposição), elas acontecem sendo restringidas por questões de ordem linguística. Portanto, a pesquisa relatada aqui traz elementos da análise da extensão da sobreposição, que tipos de sobreposição são possíveis e como um sistema linguístico precisa ser projetado para explicar estes elementos considerando dois aspectos linguísticos: as construções passivas e causativas.

A tarefa de elicitação de sobreposição de línguas consistia em apresentar para os participantes Codas, uma sequência de imagens que compunham uma cena (no exemplo abaixo, as imagens 1, 2 e 3). A seguir, os participantes viram uma imagem com quatro alternativas de resposta (4), sendo que a alternativa que melhor descrevia a cena estava destacada na cor verde e as outras eram 
distratores. A partir dessa seleção, os participantes foram requisitados a sintetizar em uma sentença o que viram na sequência de imagens. Uma pessoa junto com o aplicador da tarefa recebe uma ficha com as mesmas alternativas, mas sem marcação (5), para quem os participantes sintetizam a imagem destacada relacionada com as imagens vistas anteriormente. A pessoa que recebe a sentença produzida precisa reconhecer o que foi dito na sua ficha sem marcação.

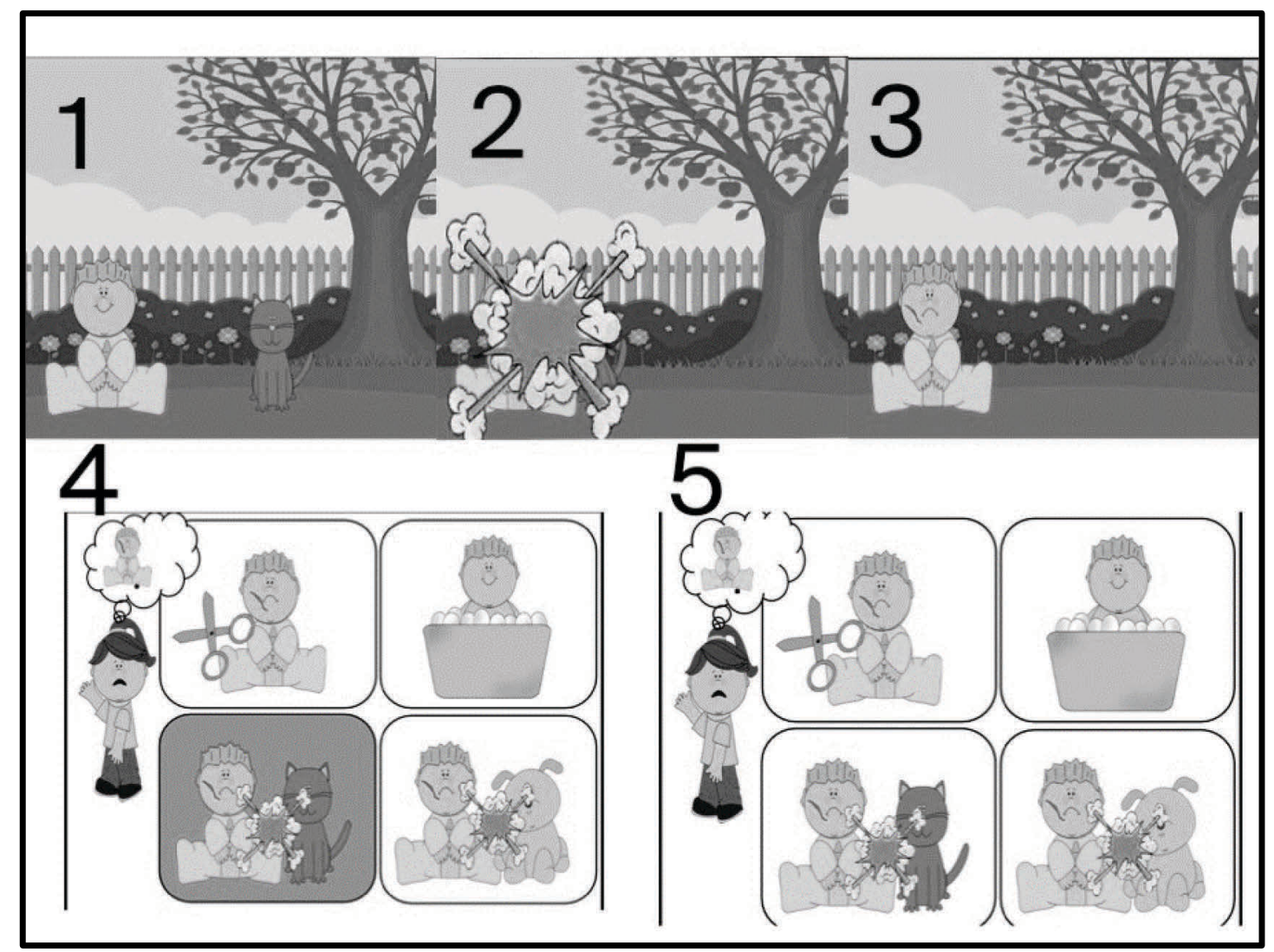

Figura 2: Exemplo de item da tarefa de elicitação Sentença alvo "o bebê foi arranhado pelo gato"

Fonte: Elaborado pelos autores (2020)

Para a produção das sentenças, a aplicadora interagia encorajando a produção bimodal e utilizando, também, sobreposição. Essa interação foi importante e muitas vezes foram necessárias intervenções e reiterações para que o participante produzisse uma resposta esperada, ou seja, que a sentença se aproximasse às sentenças-alvo pré-formuladas para cada cena, com aspectos linguísticos a serem considerados na análise de sobreposição de línguas. Depois, a outra aplicadora tinha uma ficha com as quatro alternativas sem nenhum tipo de destaque e deveria apontar qual a imagem correspondente à sentença sobreposta produzida pelo participante. No caso específico em análise neste artigo, foram selecionadas as sentenças passivas e causativas que foram produzidas ao longo da tarefa.

Para este trabalho, nosso objetivo foi de analisar a estrutura linguística destas estruturas produzidas simultaneamente em Libras e no Português buscando identificar se estas construções são passíveis de serem explicadas a partir do modelo de síntese, assim como identificar possíveis restrições que se apliquem a este modelo. 


\section{CONSTRUÇÕES CAUSATIVAS}

As construções causativas ocorrem quando um agente causador executa uma ação que irá modificar o estado de um elemento. Estas construções podem utilizar diferentes tipos verbais que devem influenciar na ordenação sintática. Observamos em nossos dados que a tipologia verbal apresenta efeitos distintos para a construção das sentenças sobrepostas, sendo identificados os verbos em geral e verbos manuais (handling verbs). Os verbos manuais envolvem uma configuração de mão representando um objeto manipulado e corresponde ao objeto direto, enquanto o sujeito e o objeto indireto são definidos pelos pontos inicial e final da trajetória do movimento que impõe ao objeto ser movido para antes do verbo na ASL (LIDDELL, 1980), assim como na Libras (QUADROS, 1999). Esse movimento do objeto para antes do verbo parece estar associado com a complexidade destes verbos (heavy verbs), uma vez que apresentam várias informações nas suas próprias formas. Jo Napoli et al. (2017) também identificaram que as ordenações Sujeito-Objeto-Verbo e Objeto-Sujeito-Verbo, ou seja, com o objeto antes do verbo, apresentam produtividade nas produções com verbos manuais (as autoras identificam como integrantes de predicados intensionais), tais como, PENDURAR, TRICOTAR, ATIRAR em contraste com verbos do tipo PENSAR, SONHAR, DIZER (integrantes de predicados extensionais). Esses verbos apresentam um componente icônico, pois as formas que tomam são motivadas pelos objetos a que se referem. Essa iconicidade é específica da modalidade das línguas de sinais. As causativas na Libras quando contam com verbos manuais apresentam-se em ordem diferente das causativas no PB.

Considerando que as ordenações são diferentes, os participantes utilizaram estratégias para buscar convergência entre as estruturas, mesmo quando as estruturas não coincidiram. Há a escolha de uma das línguas para reger a derivação sintática, mas também o uso de alternância pode ser uma das estratégias para manter ambas produções mais felizes, mesmo que sejam submetidas à estrutura da outra língua. Também vimos que o uso de verbos manuais favorece a escolha da língua de sinais como língua primária, enquanto que a aplicação de verbos gerais favorece o PB como língua a reger a derivação sintática. Assim, as escolhas das línguas como primária e secundária em contextos nos quais os interlocutores são bilíngues e podem alternar entre uma e outra língua primária podem ser influenciadas pelo tipo de estrutura sintática a ser derivada. Os bilíngues bimodais parecem escolher a língua primária de modo a favorecer a produção de sentenças bimodais mais informativas observando condições felizes de produção no ato da interação.

No exemplo $1^{1}$, temos uma construção em que CHUTAR e QUEBRAR são verbos em geral, gerando uma construção SVO em ambas as línguas, mas ao incluir um sinal descritivo visual, o sinalizante alternou as línguas, ao invés de sobrepô-las.

\section{$\underline{\text { EXEMPLO } 1}$}

HOMEM

O menino
CHUTAR

chutou a bola
DV (quadrado)

JANELA

na janela
QUEBRAR

e quebrou
VIDRO

o vidro

No exemplo 2, FUTEBOL2 se refere à ação praticada pelo agente, correspondendo a um verbo sobreposto no português "jogando bola”. Nos dois casos, foi observado que o agente foi pronunciado em ambas as línguas (HOMEM/O menino e CRIANÇAHOMEM/ O menino).

\section{$\underline{\text { EXEMPLO } 2}$}

CRIANÇA-HOMEM

O menino
FUTEBOL2

jogando bola
DV(chutar-bola)

chutou
QUEBRAR

VIDRO

quebrando o vidro

\footnotetext{
${ }^{1}$ Todos os exemplos apresentam um link com o vídeo em Libras.
} 
Assim, a tendência é de que a Libras siga a estrutura do Português e, neste caso, o participante pronuncia o agente, o causador da ação, de modo a manter as sentenças mais compreensíveis, mesmo que não totalmente gramaticais na língua secundária. Diferente desses casos, as construções com verbos manuais alteraram a ordem SVO, sugerindo que prevalece a estrutura da Libras e a sentença em Português acomoda-se sintaticamente a ela.

No exemplo 3, a ação de pegar um balde e colocar a neve dentro dele é articulada a partir dos verbos manuais: DV (pegar-balde) e DV (colocar-balde). Note-se que aqui a ordem é $\mathrm{O}(\mathrm{S}) \mathrm{V}$, já que primeiro o objeto NEVE, que sofre a ação, é pronunciado no início da sentença em ambas as línguas. Em seguida, uma sequência de verbos manuais descreve a ação de alguém (S) pegar o balde, colocar a neve no balde (V) e a consequência (DERRETER ÁGUA/ aí derreteu). Ou seja, aqui o Português precisou se acomodar à estrutura da língua principal, a Libras, que é favorecida ao serem usados verbos manuais.

\section{EXEMPLO 3}

$\begin{array}{cccc}\text { NEVE } & \text { DS (neve) } & \text { DV (colocar-balde) } & \text { DERRETER } \\ \text { Neve } & \text { pegou } & \text { e botou num balde } & \text { aí derreteu }\end{array}$

Outra característica interessante é que o sujeito, que coincide com o agente causador (S), não é pronunciado nas duas línguas. Isto parece indicar que esse tipo de construção com verbos manuais, pelo fato de incorporarem simultaneamente a ação e o agente, não demonstra a necessidade de marcação de sujeito explícita. Nas imagens apresentadas aos participantes, um menino é o agente causador que pega a neve e coloca no fogão para derreter.

Há ainda um caso identificado em que não há acomodação de uma língua à outra. Na Libras, DV(balde) NEVE é claramente o objeto da sentença na posição de tópico no exemplo 4. A participante sinaliza o objeto (o balde de neve), depois o verbo manual que inclui de uma só uma vez o agente(S) e a ação do balde sendo colocado no fogão (V). O agente é incorporado no verbo manual em Libras, enquanto que em Português não há um agente. Neste caso, houve uma tentativa por parte do falante/sinalizante de produzir as duas sentenças o mais próximas possíveis em termos fonológicos, mas este esforço teve um efeito morfossintático na sentença em português. O resultado foi a produção de uma sentença na qual 'o balde de neve' é o que está no fogão para ser derretido, em termos sintáticos, e não a 'neve', uma vez que o uso do morfema marcando gênero em 'derretido' concorda com 'balde' e não com 'neve'. A tentativa em adaptar as línguas, uma a outra, mantendo a gramaticalidade nas duas causou este efeito, embora a informatividade seja mantida.

\section{$\underline{\text { EXEMPLO } 4}$}

$\begin{array}{ccccc}\text { DV (balde) } & \text { NEVE } & \text { DV (colocar-balde-fogão }) & \text { FOGO_ } & \text { DILUIR } \\ \text { O balde } & \text { de neve } & \text { está } & \text { no fogão } & \text { para ser derretido }\end{array}$

A sentença causativa 5 com verbo manual segue a estrutura SVO em Português e SOV em Libras na sentença subordinada, apresentando incongruência. Neste exemplo, a incongruência entre BARCO e afundar talvez aconteça porque na sequência foi usado um classificador manual, AFUNDAR-BARCO, assim, a falante/sinalizante introduz o SINAL referente ao classificador de entidade que irá pronunciar na sequência. Aqui a pronúncia do agente em ambas estruturas está explícita.

\section{EXEMPLO 5}

$\begin{array}{ccccc}\text { HOMEM } & \text { REUNIÃO } & \text { DECIDIR } & \text { BARCO } & \text { AFUNDAR-BARCO } \\ \text { Homens } & \text { na reunião } & \text { decidiram } & \text { afundar } & \text { um barco }\end{array}$


Portanto, os resultados mostram duas estruturas causativas possíveis com base na tipologia verbal nas sentenças sobrepostas apresentadas. Ora o Português é a língua que rege a derivação sintática: isso ocorre especialmente nos verbos que geram uma sentença com ordem SVO com agente pronunciado. Já nos verbos manuais, a tendência é de a Libras ser a língua primária e, nestes casos, a ordem pode ser OSV com o objeto na posição tópico. Além disso, uma vez que os verbos manuais sinalizam a ação sofrida pelo objeto e ao mesmo tempo implicitamente incorporam o agente causador, não há a obrigatoriedade de pronunciá-lo.

Estas construções causativas revelam que há alternâncias na escolha da língua primária pelos bilíngues bimodais e são feitas acomodações sintáticas de uma língua para outra, gerando a síntese no processo de derivação de uma sentença única. Portanto, nas construções causativas em Português e Libras geradas a partir deste estudo, ocorrem por meio da congruência de línguas que pode ser explicadas a partir do modelo de síntese, mesmo que as estruturas sejam diferentes. No nível sintático, o fato de os verbos manuais incorporarem o objeto favorece o pronunciamento do objeto em Português juntamente com o verbo manual, pois os traços do objeto estão presentes no próprio verbo e isso é usado como estratégia pelos sinalizantes. Percebemos que há uma adaptação de uma língua a outra para potencializar a comunicação, mesmo que isso tenha um custo maior. A tendência, assim como Sorace (2011) verificou para outros pares de línguas, é de adaptação da produção bilíngue para buscar alternativas mais comunicativas. A estratégia usada nestas sentenças é de acomodação de uma língua a outra, na qual uma das línguas torna-se primária e a outra língua segue sua ordenação. O fato de os verbos manuais encapsularem o agente e a forma do objeto referente facilita a recuperação da informação na Libras tornando a produção inteligível e mantendo-se então a ordem SVO do português, porque a estrutura computada está nesta ordem.

\section{CONSTRUÇÕES PASSIVAS}

Nas línguas de sinais, as construções passivas em ASL foram estudadas por Janzen et al. (2001). Os autores argumentam que nestas, o sinalizante apresenta o evento do ponto de vista do paciente e o agente, entendido como executor da ação, é rebaixado, podendo mesmo não ser mencionado por ser desconhecido ou irrelevante. Nas construções passivas em ASL, o corpo do sinalizante referese ao paciente e o movimento das mãos à ação praticada pelo agente. Este movimento do verbo é comumente associado ao agente ainda que ele seja rebaixado e o paciente, em posição de destaque na sentença, é imóvel. Em uma construção passiva, quando o agente não é especificado, o movimento dos verbos de concordância inicia em um lócus morfossintático, mas semanticamente vazio. Janzen el al. (2001) referem-se ainda às construções passivas com role shifting. No role shifting, há uma mudança na direção do tronco e do ombro para marcar a troca de papéis de personagens em narrativas. No caso das passivas, a mudança de perspectiva do role shifting ocorre de agente para paciente. Os autores também comentam outro tipo de construção em ASL que está relacionada à passiva: um agente não especificado em um plano alto é articulado junto com um verbo com movimento para cima e para longe do sinalizador, construção que também é conhecida na literatura como high lócus. No presente estudo, identificamos características bastante semelhantes a estas descrições na Libras. No entanto, verificamos que em Libras, na produção de uma estrutura com role shift associada com verbos com concordância ou manuais ao tomar o corpo do sinalizante associado ao role shift como paciente da ação, sempre há um agente, mesmo que omitido em função da forma dos verbos. Sendo assim, a estrutura gerada não é de passiva, pois o agente da ação continua sendo o sujeito, apesar de ser um sujeito-nulo, uma vez que a Libras é uma língua pro-drop (QUADROS, 1995).

Ainda com relação à construção de passivas em ASL, outro estudo é o de Villanueva (2010) que analisa sentenças de tarefa de elicitação, de tradução de passivas em inglês para ASL. A autora não encontrou diferença entre os verbos das sentenças com agente desfocado daquelas sentenças com foco no agente, além de o paciente não aparecer em posições sintáticas diferentes das sentenças com agente focado. Não expressar abertamente o sujeito foi considerada a principal estratégia para desfocar o agente. As sentenças em ASL com agente desfocado mostram: 1. Sujeito não-declarado; 2. Conceptual Blending, com depicting signs e construções classificadoras; 3. Surrogate blending= R-loci; 4. Verbos indicadores/de concordância; 5 . Respostas às questões retóricas (questõesrh); 6. Forma lexical não especificada, tal como um pronome. Os principais traços de desfocagem do agente identificados por Villanueva (2010) são falta de proeminência e falta de especificidade e os tipos verbais influenciam no status do agente. Os verbos simples mostram relações entre um agente e um paciente que não mencionam a identidade do agente e o resultado é uma construção 
em que o agente é desfocado. Já os verbos indicadores (com concordância) possuem uma referência espacial com seus trajetos revelando proeminência mesmo quando a identidade não é declaradamente especificada e isso resulta em uma construção com foco reduzido. Da mesma forma, as construções classificadoras (depicting signs incluindo os verbos manuais) como uma representação da ação de um substituto indicando o agente de forma visualmente proeminente, que pode ser produzido sem mencionar a identidade do agente substituto; o resultado da interação entre uma alta proeminência e uma baixa especificidade é uma construção com foco reduzido no agente. Na comparação entre as sentenças em ASL sem agente declarado e a passiva em inglês, a autora argumenta que ambas têm função de desfocar o agente, que tanto em ASL como no inglês não existe um marcador morfofonológico para a passiva; não existe mudança na trajetória e locação dos referentes (não há um movimento do objeto para a posição do sujeito). Os sinalizantes em ASL, ao usarem expressões sem sujeitos nominais, deixam a posição gramatical de sujeito, que é a mais proeminente, vazia e a identidade do agente não especificada. Essa combinação de falta de especificidade e falta de proeminência resulta em uma construção em que o agente é completamente desfocado. Concluindo, enquanto a ativa em ASL tem o sujeito declarado, a passiva em ASL tem um sujeito não-declarado, no contexto que o sujeito não foi previamente expresso no discurso. Se o sujeito já foi estabelecido no discurso é diferente da construção com agente desfocado, pois traz status diferentes para o agente. No caso da Libras, verificamos que apesar de haver o uso do que a autora refere como sujeito desfocado, o tipo de estrutura produzido em Libras não é de uma verdadeira passiva, pois mesmo que o sujeito seja indeterminado (que é o caso da maioria dos exemplos citados por Villanueva (2010) ao referir sujeitos desfocados), do ponto de vista sintático, há um sujeito agentivo gramatical, mesmo que não esteja determinado ou pronunciado. O uso de sujeitos indeterminados é uma das estratégias usadas pelos sinalizantes de Libras para sobrepor a Libras a estruturas passivas em PB.

No Português, as construções passivas são aquelas em que o sujeito da frase ativa se torna o agente e o objeto da sentença ativa se torna o sujeito de um verbo que combina o auxiliar 'ser' e o particípio passado do verbo transitivo. Esta é uma das formas de construção da passiva no Português. O agente da passiva, nessa língua, também pode ser apagado (DUBOIS et al., 2006).

Ao observamos a produção das sentenças pelos participantes Codas bilíngues bimodais, procuramos identificar se havia alguma estrutura na Libras para a construção passiva, combinada com a passiva do Português. Identificamos a utilização de estratégias para ajustar a Libras à estrutura passiva do Português que tornaram a estrutura da Libras também adequada, com convergência e adaptação à estrutura passiva do PB, mesmo não havendo uma verdadeira construção passiva na Libras. Entre elas, vimos o uso do sujeito indeterminado, a omissão do sujeito para não conflitar com o material fonológico pronunciado no PB e da alternância das estruturas sintáticas da Libras e do PB, ao invés da sobreposição, favorecendo a alternância das estruturas sintáticas da Libras e do PB.

Um tipo de construção observado é o de passivas no Português sobrepostas a uma estrutura em Libras em que verbos são produzidos com movimento down-up ou up-down. Estas construções na Libras possuem um sintagma determinante (DP) localizado em uma área alta (high locus), ou seja, um ponto alto no espaço de sinalização. Neste caso, os sujeitos são interpretados como indeterminados, pois não são especificados pelo sinalizante.

Este é o caso do exemplo 6, porque a sentença na Libras segue a mesma ordem da sentença passiva no Português, no entanto o verbo ASSALTAR é produzido com um movimento do espaço neutro em direção à cabeça (de baixo para cima). Este movimento é feito em um ponto alto do espaço e o sujeito indeterminado na Libras que não é pronunciado em função da sua indeterminação, viabilizando a sobreposição com o $\mathrm{PB}$ na estrutura passiva que rege esta derivação. Parece que os sinalizantes estão tentando produzir uma estrutura adequada na Libras enquanto produzem a passiva no Português, isto porque, com base na imagem visualizada, não era possível identificar o agente da ação em ASSALTAR. Em Libras, o uso do role shift também foi usado e justificase pela própria natureza do verbo direcional referindo-se à ação sofrida por um paciente animado. 
EXEMPLO 6

$\begin{array}{ccc}\text { HOMEM } & \text { ASSALTAR } & \text { RUA } \\ \text { Um homem } & \text { foi assaltado } & \text { na rua }\end{array}$

Da mesma forma, no exemplo 7, a construção em Libras que se sobrepõe à passiva no Português possui um movimento produzido de cima para baixo, em direção ao espaço neutro, ao se referir a uma entidade inanimada (LOJA) mas sem especificar quem praticou a ação. O exemplo 7 apresenta uma estrutura de high locus, porém não é role shift, já que o verbo direcional, junto com o paciente inanimado (a loja) direciona-se para o espaço neutro e não para o corpo do sinalizante.

\section{EXEMPLO 7}

$\begin{array}{ll}\text { LOJA } & \text { ASSALTAR } \\ \text { A loja } & \text { foi assaltada }\end{array}$

A estrutura para cima (up) em Libras também mostrou a possibilidade de combinação com a sentença impessoal em Português, como no exemplo 8, no verbo manual DV (pegar-carteira).

\section{EXEMPLO 8}

$\begin{array}{ccccc}\text { ROUBAR } & \text { DV(pegar-carteira }) & \text { DV(pegar-carteira }) & \text { ROUBAR } & \text { DV(pegar-carteira) } \\ \text { Roubaram } & \text { a carteira da } & \text { roubaram } & \text { a } & \text { carteira }\end{array}$

Os exemplos acima mostram estratégias que permitem sobrepor a Libras e o Português, com estruturas adequadas em ambas as línguas, tanto combinada com a forma passiva quanto à forma impessoal em Português.

Barberà e Hofherr (2017) analisam as construções com movimento para cima (up) como high-locus construction, em língua de sinais catalã. As autoras afirmam que sentenças desse tipo não se comportam exatamente como passivas, por não envolverem redução de transitividade e por não haver evidências de que o objeto seja reduzido a sujeito. Então argumentam que nestas construções há uma referencialidade deficiente do sujeito, sem qualquer mudança na transitividade, comparável a uma construção sem sujeito especificado. Esta conclusão de Barberà e Hofherr (2017) parece também ser observada na Libras, uma vez que notamos que estas estruturas mantêm o sujeito gramatical que originalmente é agente, diferente do processo de passivação que acontece no PB.

Como mostramos nos exemplos de 5 a 8 , a construção em Libras sobrepõe-se tanto à passiva quanto à forma impessoal no Português. Esta sobreposição evidencia uma acomodação da Libras ao Português, mas há uma tentativa de adaptação dentro das possibilidades linguísticas disponíveis de produzir a Libras da melhor forma possível (a la SORACE, 2011). Neste sentido, a estrutura gramatical gerada é de passiva ou de impessoal e a acomodação dos itens lexicais da Libras no nível fonológico (após spell-out) é combinada acomodando o conteúdo fonológico sem comprometimento desta estrutura. Em relação ao impessoal, torna-se mais fácil compatibilizar as estruturas, mas em relação à passiva vemos que material lexical é omitido de uma língua para permitir a checagem da estrutura com o material lexical da outra língua, minimizando o comprometimento das estruturas pronunciadas em ambas línguas.

As autoras distinguem duas estruturas de agente de fundo na língua de sinais catalã: construções high-locus e as construções centrais sem concordância. Nas construções high-locus não há um agente expresso, o verbo é flexionado (verbos de concordância ou simples), a concordância entre um high-locus e um agente não foi previamente ativada; o corpo do sinalizante tem função de paciente (com pacientes animados) ou a sinalização é feita no espaço neutro (com pacientes inanimados); com pacientes animados pode ser feito um role shift do sinalizante ao paciente marcado pelo desvio do olhar e inclinação do corpo. Exemplo: POLICEMAN 3up- 
HIT-1. Nas construções centrais sem concordância, o agente não é expresso, o verbo não é flexionado, o paciente é inanimado, o sinal é articulado no espaço neutro em frente ao sinalizador e frequentemente é usado o marcador "ALREADY”. Exemplo: HOUSE BUYc ALREADY. Nas construções high-locus, foram identificados tanto verbos de concordância como verbos simples, mas as construções centrais sem concordância são limitadas a verbos simples. Em um verbo simples como QUEBRAR, se articulado no espaço neutro em frente ao sinalizador, é interpretado como a articulação default do verbo, ou seja, uma construção central sem concordância. No entanto, ele pode ser articulado com inclinação do corpo e high locus e esta configuração é interpretada como um agente humano não específico. Na Libras, mesmo que não haja a inclinação, há o role-shift que fica registrado por meio do uso do corpo do sinalizante, podendo ser mais proeminente ao ser associado à inclinação ou elevação dos ombros.

Outro conjunto de exemplos que ilustra esta relação com estruturas em que há pacientes animados também mostrou que é possível sobrepor a passiva do PB a uma estrutura que parece ser utilizada como passiva na Libras; são os casos de role-shift nos verbos manuais. Na verdade, vemos que a estrutura com role-shift é agentiva na Libras, mas a sobreposição é possível porque o role-shift ocupa a posição do agente sem afetar a estrutura gramatical de passiva do Português permitindo a sobreposição. Sempre em que há o role-shift, o paciente é o corpo do sinalizante para o qual o movimento do verbo é direcionado.

\section{EXEMPLO 9}

$\begin{array}{lcll}\text { HOMEM } & \text { DV (risco) } & \text { DV (garra) } & \text { GATO } \\ \text { O menino } & \text { foi machuc[ado] } & \text { arranhado } & \text { pelogato }\end{array}$

\section{$\underline{\text { EXEMPLO } 10}$}

$\begin{array}{cccc}\text { BEBÊ } & \text { DV (risco) } & \text { IX (esse) } & \text { GATO } \\ \text { Um bebê } & \text { foi arranhado } & \text { pelo } & \text { gato }\end{array}$

As estruturas acima mostram que foram produzidas sentenças sobrepostas que evidenciam a compatibilização das línguas, mesmo com estruturas diversas. A estrutura gramatical gerada na passiva do PB é preenchida com material da Libras de forma sobreposta sem ser comprometida do ponto de vista gramatical, pois há um esforço do sinalizante em produzir em ambas as línguas estruturas o mais aceitáveis possível.

Outra possibilidade encontrada foi a de produzir passiva ou impessoal em PB, com a Libras apenas se submetendo à estrutura do Português, ou seja, os sinais seguiram a ordem da sentença em PB, não produzindo uma sentença sobreposta completa, uma sobreposição parcial com alternância entre as línguas para tentar salvar a produção da outra língua de forma mais aceitável possível, novamente adaptando uma língua a outra (a la SORACE, 2011). Nesses casos, o PB é a língua que rege a derivação sintática.

\section{$\underline{\text { EXEMPLO } 11}$}

HOMEM

O cara
ROUBAR

foi roubado 


\section{EXEMPLO 12}

$\begin{array}{lll}\text { ROUBAR } & \text { CARTEIRA } & \text { HOMEM } \\ \text { Roubaram } & \text { a carteira } & \text { do homem }\end{array}$

\section{EXEMPLO 13}

\begin{tabular}{|c|c|c|c|c|}
\hline & QUEBRAR & ROUBAR & QUEBRAR & ROUBAR \\
\hline A loja foi & quebr[ada] & assaltada & quebrada & por assaltantes \\
\hline
\end{tabular}

Há também uma tendência de produção de sentenças causativas em Libras, o que pode ser uma evidência de produção de causativa no lugar da passiva, influenciando também na transformação do Português em causativa. Desta forma, há uma tentativa de conciliar o Português com a Libras, com ajustes para que ambas as línguas sejam realizadas na forma causativa e se evite a construção passiva, provavelmente por ser mais natural produzir causativa em Libras. Então há uma reorganização da sentença em Libras na forma causativa, que influencia também o Português. As sentenças abaixo são um exemplo, com a causativa sendo produzida em Português e a não marcação do verbo manual em Libras.

\section{EXEMPLO 14}

$\begin{array}{lll}\text { GATO } & \text { DV (garra) } & \text { BEBÊ } \\ \text { Ogato } & \text { arranhou } & \text { o bebê }\end{array}$

Outra possibilidade de tentativa de reorganização da Libras e do PB à estrutura causativa pode gerar omissão de elementos de uma das línguas, com o acarretamento de incongruências ao sobrepor as duas línguas. No exemplo abaixo, houve produção de efeito sonoro no lugar do verbo em PB sobreposto ao verbo manual em Libras. Os efeitos sonoros indicam o uso de ações construídas gestuais que são recursos visuais gramaticalizados na Libras enquanto resultado da modalidade da língua visual-espacial. Esses efeitos sonoros associados aos verbos manuais foram também identificados por Quadros et al. (2019).

\section{$\underline{\text { EXEMPLO } 15}$}

\begin{tabular}{|c|c|c|c|c|}
\hline HOMEM & ESTAR & BRINCAR & GATO2 & DV(garra) \\
\hline O menininho & estava & brincando & e o gato & s.e. (tsss) \\
\hline
\end{tabular}

Uma outra estrutura encontrada foi quando o participante produziu uma passiva no PB, inicialmente seguindo a estrutura do Português com sobreposição da Libras, seguida de alternância para a Libras com marcação para cima sem sujeito definido, como podemos observar no exemplo (16). Este é um exemplo de alternância de línguas. Ele passa para a Libras para fazer o verbo manual para cima e parece que reanalisa a própria produção em Libras mantendo a passiva do Português, viabilizando a sobreposição das duas línguas de forma mais aceitável possível, sem ofender a estrutura derivada. O exemplo (15) sobrepôs o efeito sonoro que é um tipo de produção icônica oral ao material icônico lexicalizado da Libras sem marcar a agentividade no PB que está presente na Libras por meio do sinal produzido. No caso do exemplo (16), o material em PB não foi pronunciado ao haver esta mesma produção icônica lexical em Libras que marca a agentividade da sentença que não está presente no PB. Estas duas possibilidades permitem a sobreposição e a alternância das línguas garantindo a adequação das produções para fins comunicativos. 


\section{EXEMPLO 16}

HOMEM

MULHER

DV(pessoa-movimento)

É

ROUBAR

DV(puxar-cima)

NÃO-VER

HOMEM

Um rapaz

no meio da multidão

foi

roubado

e ele não percebeu

Identificamos, portanto, as seguintes formas de sobreposição da Libras a estruturas passivas em PB:

1. Passivas ou impessoais em Português + Libras seguindo a estrutura do Português ou não realizando blending completo.

2. Passivas em Português + Libras com high locus com role-shift associado ao paciente da passiva ou role-shift associado ao agente na direção do paciente da passiva inanimado.

3. Passivas em Português + Libras com verbos manuais com role shift preservando a agentividade por meio da animacidade associada ao corpo do sinalizante no role shift.

A alternância de línguas também pode ser empregada para evitar sobreposições incongruentes e, também, o uso de efeitos sonoros associados às construções descritivas visuais na Libras permite a sobreposição sem conteúdo associado a conteúdo gramatical favorecendo a síntese.

\section{CONCLUSÃO}

O presente estudo procurou observar como Codas adultos produzem estruturas causativas e passivas sobrepondo Libras e Português, com o objetivo de verificar se estas construções poderiam ser explicadas pelo modelo de síntese, bem como identificar possíveis restrições, utilizando para tal uma tarefa de elicitação de sobreposição das duas línguas. Foi observado o caso de apenas uma das línguas ser escolhida para reger a derivação sintática ou haver alternâncias entre uma ou outra estrutura. No primeiro caso, uma língua é escolhida como primária e a outra ajusta-se da melhor forma possível àquela estrutura. No segundo caso, também se observa o esforço para produzir de forma compreensível em ambas as línguas.

No caso das construções causativas, a tipologia verbal influenciou na construção da sentença. Os exemplos que mostramos elucidaram algumas possibilidades de estratégias para a tentativa de produção de boas sentenças em ambas as línguas: causativa SVO com descritivo visual, que alternou duas línguas no lugar de sobrepô-las; SVO em ambas as línguas com agente pronunciado em Libras e PB; mudança na ordem SVO em Libras quando é produzido verbo manual, com PB acomodando-se sintaticamente à Libras; marcação de sujeito não explícita nas duas línguas, em sentenças com verbos manuais; não acomodação de uma língua a outra, embora mantida a informatividade; causativa com verbo manual e agente explícito em ambas, apresentando incongruência pois gerou SVO em PB e SOV em Libras. As causativas na Libras geralmente seguiram a ordem do Português (SVO) nas sentenças com verbos em geral, no entanto naquelas com verbo manual, há mudança na ordem, com movimento do objeto para antes do verbo, ou seja, a ordem da Libras fica diferente da causativa em PB. Assim, concluímos que o verbo manual favorece a Libras como língua primária e os verbos gerais favorecem o PB.

Nas construções passivas, a ideia era verificar se havia alguma estrutura na Libras que fosse compatível com as passivas no PB. O que foi observado não foi uma verdadeira passiva em Libras, mas estratégias possíveis para sobrepor a Libras à estrutura passiva do PB. Assim, foram construídas passivas no Português com movimento do verbo em Libras localizado em uma área alta (high locus), interpretados como sujeitos indeterminados por não serem especificados. Com relação à ação sofrida por um paciente animado, também foi produzido em Libras um role shift, associado a um verbo direcional, indicando o paciente que sofre a ação descrita. Neste caso, ainda assim há um agente da ação que continua sendo o sujeito, mesmo que este seja um sujeito nulo. Quando o sinalizante se refere a uma entidade inanimada foi produzida uma outra possibilidade, um movimento do verbo direcional produzido de cima para baixo em direção ao espaço neutro, não sendo possível também identificar quem praticou a ação. Esta 
mesma estrutura também foi possível combinar com uma sentença impessoal do PB. A sobreposição, nestes casos, mostra a acomodação da Libras à estrutura passiva ou impessoal do PB, havendo compatibilização das línguas. Foi observada também uma tendência de produção de causativas em Libras no lugar da passiva, evitando esse tipo de construção; a presença de incongruências na tentativa de reorganização da Libras e do PB à estrutura causativa gerando perdas de elementos de uma das línguas; ou alternância das línguas, quando o participante começa a produzir uma passiva no PB seguindo a estrutura dessa língua mas depois alterna para Libras como língua primária, reanalisando a produção em Libras e mantendo a passiva do PB. Sintetizamos, então, três formas possíveis de sobreposição da Libras à passiva do PB: (i) Libras seguindo a estrutura passiva do PB ou não realização de blending completo; (ii) Libras com high locus e role shift associado ao paciente animado ou role shift associado ao agente em direção ao paciente inanimado em direção ao espaço neutro; (iii) Libras com verbos manuais e role shift, preservando a agentividade pela animacidade associada ao corpo do sinalizante. Sendo assim, observou-se que estas estruturas em Libras que se sobrepuseram às passivas do PB, apesar de não serem verdadeiras passivas, tornaram a Libras também adequada.

Os resultados sugerem que os bilíngues bimodais, ao produzirem sentenças causativas e passivas sobrepondo Libras e PB, valem-se de uma série de estratégias para alcançar uma convergência consistente entre as produções das duas línguas, com o intuito de haver uma boa interação comunicativa. Assim, eles escolhem uma língua como primária, que irá gerar a derivação, enquanto a outra procurará uma forma de se ajustar à primeira estrutura. Há também tentativas de busca de convergência de sentenças aceitáveis sem infringir a síntese de línguas, mesmo com estruturas gramaticais tipicamente diferenciadas entre as línguas, que é o caso de produções causativas e passivas no par de línguas analisado, Libras e PB. Quando isso acontece, há o uso de estratégias para evitar a sobreposição de sentenças incongruentes. Para isso, o uso de alternância de línguas, a sobreposição parcial das línguas e o preenchimento lexical da língua secundária podem ser opções produzidas para evitar produções não gramaticais nas línguas sobrepostas. Além disso, a opção gramatical mais convergente será a opção para a sobreposição. Conclui-se, então, que parece haver uma tendência para a produção de sentenças causativas em Libras ao invés de estruturas passivas. Quando no Português é produzida uma sentença passiva, a sentença em Libras se torna ininteligível por utilizar a ordem do Português. Em alguns casos de passiva no Português, o sinalizante utilizou-se de estratégias em Libras, como o uso do impessoal (up) ou role shifting. Estas foram estratégias usadas para produzir sentenças sobrepostas em Libras e PB. Mas, de modo geral, a tendência é a produção de causativas em Libras e isso é confirmado na produção dos dados dos surdos - grupo controle. Quando veem a sentença escrita em Português, os surdos produzem uma sentença em Libras causativa.

\section{REFERÊNCIAS}

BARBERÀ, G.; HOFHERR, P. C. Backgrounded agents in Catalan Sign Language (LSC): Passives, middles, or impersonals? Language, Baltimore, v. 93, n. 4, p. 767-798, 2017.

BISHOP, M.; HICKS, S. Orange Eyes: Bimodal bilingualism in hearing adults from Deaf families. Sign Language Studies, Washington, v.5, p. 188-230, 2005.

CHOMSKY, N. The Minimalist Program. Cambridge, MA: MIT Press, 1995.

DUBOIS et al., 2006. Dicionário de Linguística. São Paulo: Cultrix, 2006.

EMMOREY, K. et al. Bimodal bilingualism. Bilingualism: Language and Cognition, Cambridge, v. 11, n.1 p. 43-61, 2008.

HALLE, M.; MARANTZ, A. Distributed Morphology and the pieces of inflection. In: HALE, K; KEYSER, S. J. (org.). The View from Building 20: Essays in honor of Sylvain Bromberger. Cambridge, MA: MIT Press, 1993. p. 111-176.

JANZEN, T.; O’DEA, B.; SHAFFER, B. The Construal of Events: Passives in American Sign Language. Sign Language Studies, Washington, v. 1, n. 3, p. 281-310, 2001. 
LIDDELL, S. American Sign Language Syntax. The Hague: Mouton Publisher, 1980.

LILLO-MARTIN, D. et al. Bimodal bilingual cross-language influence In unexpected domains. In: COSTA, J; CASTRO, A.; LOBO, M.; PRATAS, F. (org.). Language Acquisition and Development: Proceedings of GALA 2009. Newcastle upon Tyne: Cambridge Scholars Press, 2010. p. 264-275.

LILLO-MARTIN, D.; QUADROS, R. M. de; CHEN-PICHLER, D.; Language choice in bimodal bilingual development. Frontiers in Psychology, Lausanne, v. 5, n. 1163, p. 153-167, out. 2014.

LILLO-MARTIN, D.; QUADROS, R. M. de; CHEN-PICHLER, D. The development of bimodal bilingualism: Implications for linguistic theory. Linguistic Approaches to Bilingualism, John Benjamins Publishing Company, Amsterdã, v. 6, p. 719-755, 2016.

MACSWAN, J. The architecture of the bilingual language faculty: Evidence from code- switching. Bilingualism: Language \& Cognition, Cambridge, n. 3, p. 37-54. 2000.

MACSWAN, J. Codeswitching and generative grammar. Bilingualism: Language \& Cognition, Cambridge, v. 8, n. p. 1-22, 2005.

NAPOLI, D. J.; SUTTON-SPENCE, R.; QUADROS, R. M. de. Influence of Predicate Sense on Word Order in Sign Languages: Intensional and Extensional Verbs. Language, Baltimore, v. 93, n. 3, p. 641-670, 2017.

PIERANTOZZI, C. Agreement within early mixed DP. In: BRAUNMÜLLER, K.; GABRIEL, C. (org.). Multilingual Individuals and Multilingual Societies. John Benjamins, Amsterdã, 2012. p. 137-152.

POPLACK, S. Sometimes I'll start a sentence in Spanish Y TERMINO EN ESPANOL: Towards a typology of code-switching. Linguistics, Mouton Publisher, The Hague, v. 18, p. 581-618, 1980.

PRESTON, P. Mother Father Deaf: The heritage of difference. Social Science and Medicine, Amsterdã, v. 40, n.11, p.1461-1467, 1995.

QUADROS, R. M. As categorias vazias pronominais: uma análise alternativa com base na Libras e reflexos no processo de aquisição. 1995. Dissertação (Mestrado em Letras) - Programa de Pós-Graduação em Letras, Pontifícia Universidade Católica do Rio Grande do Sul, Porto Alegre, 1995.

QUADROS, R. M. de. Phrase Structure in Brazilian Sign Language. 1999. Tese (Doutorado em Letras) - Programa de PósGraduação em Letras, Pontifícia Universidade Católica do Rio Grande do Sul, Porto Alegre, 1999.

QUADROS, R. M. de.; LILLO-MARTIN, D.; CHEN-PICHLER, D. Bi-national Bi-modal Bi-lingual corpora of child language. In: MELlO, H.; PETTORINO, M.; RASO, T. (org.). Proceedings of the VIIth GSCP [Gruppo di Studi sulla Comunicazione Parlata]. International Conference: Speech and Corpora, Firenze: Firenze University Press, 2012. p. 87-92.

QUADROS, R. M. de.; LILLO-MARTIN, D.; CHEN-PICHLER, D. Methodological considerations for the development and use of sign language acquisition data. In: RASO, T. MELLO, H.; PETTORINO, M. (org.). Spoken Corpora and Linguistic Studies. John Benjamins Publishers, Amsterdã, 2014. p. 84-102.

QUADROS, R. M. de. et al. Methods in bimodal bilingualism research: Experimental studies. In: ORFANIDOU, E.; WOLL, B.; MORGAN, G. (org.). The Blackwell Guide To Research Methods In Sign Language Studies. Blackwell, Nova Jersey, 2015. p. $250-280$.

QUADROS, R. M. de. ;LILLO-MARTIN, D; CHEN-PICHLER, D. Bimodal Bilingualism: Sign Language and Spoken Language. In: MARSCHARK, M.; SPENCER, P. E. The Oxford Handbook of Deaf Studies in Language. New York: Oxford University Press, $2016 \mathrm{a}$. p. $181-196$. 
QUADROS, R. M. de. ; LILLO-MARTIN, D.; EMMOREY, K. As línguas de bilíngues bimodais. Revista de Estudos Linguísticos da Universidade do Porto, Porto, v. 11, p. 139-160, 2016 b.

QUADROS, R. M. de. Língua de Herança. Porto Alegre: Penso, 2017.

QUADROS, R. M. de. Fundamentos do bilinguismo bimodal. In: MOTA, M. B.; NAME, C. (org.). Interface linguagem e cognição: contribuições da Psicolinguística. Tubarão: Copiart, 2019. p. 219-241.

QUADROS, R. M. de. et al. Code-blending with depicting signs. Linguistic Approaches to Bilingualism. John Benjamins Publishing Company, Amsterdã, p. 1-19, 2019.

SORACE, A. Pinning down the concept of "interface" in bilingualism. Keynote epistemological article. Linguistic Approaches to Bilingualism. John Benjamins Publishing Company, Amsterdã, v. 1, n. 1, p. 1-33, 2011.

VAN DEN BOGAERDE; BAKER, A. Are young deaf children bilingual? In: MORGAN, G.; WOLL, B. (org.). Directions in Sign Language Acquisition. Amsterdam \& Philadelphia: John Benjamins, 2002. p. 183-206.

VILLANUEVA, M. N. Non-agent focused constructions in American Sign Language: A Cognitive Linguistic Analysis. . 2010. Dissertation (Doutorado em Filosofia) - Department of Linguistics and the Graduate School of Gallaudet, Washington, 2010.

\section{()(1) $\circledast$}

Recebido em 18/09/2020. Aceito em 08/10/2020. 